\title{
Application of intercultural communicative competence in college English teaching
}

\author{
Huimin Zhao ${ }^{1, \text { a }}$ \\ ${ }^{1}$ Bohai university, Jinzhou, 121013 China \\ ahmzhao2008@163.com
}

Keywords: Cross-cultural communication; Cultural awareness; Teaching strategy

\begin{abstract}
Language is the carrier of culture. Culture is the core content of national life and value. Due to the large difference between Chinese and Western cultures, cross-cultural communications often fail between peoples from different cultures due to the cultural conflicts. In this article, the author put forward the strategies on cultivation of cultural awareness as well as the according teaching suggestions.
\end{abstract}

\section{Introduction}

College English Curriculum Requirements (for Trial Implementation) formally issued by Ministry of Education in China in 2004 clearly points out that college English teaching main involves English language knowledge, application skill, learning strategy and intercultural communication. It is a teaching system integrating multiple teaching modes and teaching means under the guidance of foreign language teaching theory. Therefore, the development of intercultural communicative competence inevitably becomes a focus in the current foreign language teaching. Language is the carrier of culture, while culture is the carrying contents of language, so they are inseparable. Language reflects the characteristics of a nation, which not only includes historical and cultural background of the nation, but also contains the nation's view of life, life style and thinking mode. Furthermore, culture shows a distinctive national characteristic, that is, cultural individuality. Through the language of a nation, the diverse cultural forms of this nation can be observed. Therefore, it is very necessary to introduce different cultural information into college English teaching, which is an important content in the cultivation of intercultural communicative talents. From the perspectives of long-term teaching practices, there is no doubt that besides language itself, lacking of understanding or being unfamiliar with cultural background can also influence the improvement of students' English ability. Particularly, the latter is the fundamental factor, because many linguistic phenomena are explained by cultural factors. The introduction of cultural background knowledge, on the one hand, can help teachers to adopt flexible teaching methods and choose teaching materials reasonably. On the other hand, it can stimulate students' interest in learning and enliven classroom atmospheres, thus changing students' passive learning to active use of language knowledge. In conclusion, it is of great benefits to cultivate students' cultural awareness applying appropriate principles and approaches in college English teaching.[1]

\section{Cultivation of cultural awareness}

The cultivation of cultural awareness should not be isolated from, but needs to be integrated into, daily language teaching. To realize this, it is suggested to cultivate cultural awareness from the following aspects: 1) Cultivation in daily teaching. As classroom is an important place for students to mater knowledge systematically, foreign language teachers should not only teach language knowledge but also cultivate students' cultural awareness. In this way, it is helpful for students to more effectively apply and master language and stimulate learning interest, because foreign culture is fresh and unfamiliar for students. For example, when teaching vocabularies, such as "knife", "fork", "spoon" and "plate", apart from mastering basic meanings of these words, it is more important to 
make students understand that people in western countries eat with the tableware instead of using chopsticks just like Chinese. Moreover, they use them in a particular manner: generally left for the fork and right for the knife. This series of food culture expands students' knowledge, so that students learn more about the words. Furthermore, we should pay attention to the cultivation of students' national spirits when introducing foreign cultures to make them understand that eating with chopsticks has its own advantages compared with eating with a knife and a fork. 2) Cultivation in daily life. As language comes from life, without life, language loses its vitality. In daily life, there are many language cultures. For students, a lot of target language cultures are available in their daily life. Therefore, students need to be trained to be observant and notice the target language all the time. When meeting relevant problems, students should solve in time or discuss with students and teachers.

3) Cultivation through information technology. Information technology needs to be fully used for the cultivation of cultural awareness. In the face of the Internet, students may be helpless, so it is necessary for teachers to teach them basic knowledge of information technology. At a certain stage, students can be required to complete small subjects relating to the culture of target language and demonstrate the results using pictures or texts through group cooperation. In this way, students can access to knowledge extensively and consolidate knowledge, which serves for the communication of foreign languages. The cultivation of cultural awareness as a comprehensive project, fundamentally speaking, is the cultivation of cultural quality, rather than training of merely language or communication skills. In addition, in students' learning, the input of language and culture mainly relies on the instruction of teaching materials of foreign language, classroom and teaching of foreign language teachers. Culture education in foreign language teaching should not be regarded as an additional learning content apart from listening, speaking, reading and writing. In fact, culture is always the background of language teaching and is likely to affect the teaching itself all the time. Language is a kind of social practice, while culture is the core of language teaching. Therefore, language teaching is not the training of the above four skills along with culture education, but should be the results of promoting and thinking language ability for cultural awareness and language teaching cannot be separated. In foreign language teaching, learners need to learn not only the specific target language culture or the communicative competence, but also intercultural communicative competence. Therefore, the real task of cultural acquisition in foreign language teaching is not to let learners completely integrate in another culture (culture of target language) by abandoning their original culture, but to make learners fully understand limitations of a specific culture (including target and native language cultures). Students need to learn to break the pattern and scope that a specific culture sets for communication, and coordinate the adaptability of language application in intercultural communication. By doing so, it can make both communicators not only fully speak for themselves, but also contact and understand each other maximally, so as to realize the true communication and serve for teaching objectives of college English more effectively. [2]

\section{Approaches for the cultivation of intercultural communicative competence in English teaching}

\section{Classroom teaching.}

In the classroom teaching, teachers are suggested to add relevant introduction of cultural background by combining with text contents while teaching language. Moreover, teachers also need to point out cultural significance or conventions in the utilization through comparing and explaining different languages and cultures. Therefore, according to the specific conditions, such as different teaching objects, goals, requirements and environments, teachers are expected to choose appropriate cultural contents for explanation, so as to input meaningful culture contents to students. Furthermore, through analysis of examples, the differences between Chinese and western cultures are present, thus enriching students' cultural knowledge and cultivating their intercultural communicative competence. In addition, teachers can provide conditions and create environment in classroom for students to simulate situations in real life where students play roles to conduct activities including greeting, chatting, making telephone appointment, expressing thanks and apologizing in English. For example, 
in the first lesson (Time-Conscious Americans) in the second volume of New Horizon College English for reading and writing course, students can play roles. Through these classroom activities, students can better experience the target language culture and improve awareness of language utilization. [3]

\section{Introducing culture differences along with language forms and communicative principles.}

Western contrastive linguistics shows that the best teaching materials of foreign language should scientifically describe the target foreign language and demonstrate the native language of students in parallel, and then compare them in details. Since culture is studied by learning language, the selected materials are bound to demonstrate cultural factors and material range needs to reflect the differences of two cultures. So, it is suggested to use materials showing similarity and also difference in dissimilar languages. The materials should be representative of the target language and contain contents relating to the customs, habits and behavior patterns in the western society. They should convey clear concepts of similarities and differences of foreign or bilingual cultures to students. The scope of cultural differences is very broad, and mastering it should always be accompanied with the cultivation of cultural communicative competence, being reflected in the foreign language teaching materials and involved in the whole foreign language teaching. Therefore, foreign language materials should not only conform to English learning rules, but also contain rich contextual knowledge. In the introduction of language, it is necessary to consider whether students master the target language system and communicative principles, so as to supplement the knowledge of target language and cultural background required in students' communication. Furthermore, typical intercultural communication cases also need to be analyzed, to benefit for students' intercultural communication and improve their intelligence and intercultural quality, so as to cultivate open mind in the practice of intercultural communication. For Chinese students, reading is the most reliable and abundant source of cultural knowledge. If teaching materials can consciously guide students to cultivate and improve their sensitivity to cultural differences, they are helpful to cultivate students' intercultural communicative competence and form reasonable intercultural attitude including open, equal, respectful, tolerant, and objective psychology.[4]

\section{Deepening the understanding of Chinese culture by strengthening cultural contrast}

In the global context, the wide range of social communication makes cultural teaching become an important goal of foreign language teaching. However, the task of foreign language teaching is very difficult to be accomplished only through classroom teaching of foreign language. We cannot ignore the characteristic culture traditions of Chinese as a result of highlighting the cultural traditions in the target language countries. In fact, as English constantly expands its influences, cultures of other nations are constantly competing with it, thus causing influence and interaction between the two. In other words, the contents of culture teaching in foreign language teaching in any country are intersection and contradiction of the two cultures. Intercultural education provides a good chance to examine national culture, so this advantage of intercultural education should be fully used in selecting teaching contents, so as to strengthen the cultural output (introducing and publicizing Chinese culture to foreign lands). In English education, Chinese cultural education should be strengthened to apply the comparison results of Chinese and English, such as the common core parts of the two cultures in a series of English teaching materials. Moreover, through the contrast of native and target languages, students can be aware of the essence of national culture and what can be used in target language culture. Finally, the teaching of Chinese culture is supposed to be involved as well, including teaching of vocabularies, phrases, sentences, idioms and allusions expressing Chinese characteristics. In conclusion, the purpose is to cultivate English learners' self-awareness of Chinese culture and promote students' reflections on Chinese culture.

\section{Strengthening extra-curricular reading and expanding the horizon of knowledge.}

Students need to be guided to read a large number of British and American literary works, and read original works if possible. In addition, they can broaden the utilization of information sources of computer network and the effects of language courseware based on multimedia and computers by using modern high-tech means. Teachers are also suggested to organize students to watch relevant 
movies and videos to participate in studio English activities. In this way, students can appreciate the true meaning of English culture in the real language environment and cultivate their language understanding and cultural adaptability, thus enhancing their English utilization ability and intercultural communication perception.

\section{Conclusions}

Intercultural English teaching needs to pay attention to the cultivation of students' cultural awareness, so that students are sensitive to the differences and conflicts between different cultures in intercultural communication. Meanwhile, students' intercultural communicative competence should be improved. In foreign language teaching, cultural awareness and intercultural communicative competence are inseparable. English teachers should strengthen researches on intercultural communication in college English teaching, continuously improve their culture accomplishment and deal well with the relationship between language teaching and culture. In this way, teachers can help students to understand the world and the differences between Chinese and western cultures, improve students' humanistic quality, expand their cultural vision and consciousness and develop students' intercultural communicative competence.

\section{Acknowledgements}

This work is supported by Social Science Foundation of Liaoning Province (No. L15DWW005) and Bohai University Teaching Reform Project (No.BDJG15QNB002).

\section{References}

[1] Deng Yanchang, Liu Runqing, Language and culture: comparison between English and Chinese language and culture[M]. Beijing: Foreign Language Teaching and Research Press, 1989.

[2] Zhang Lili, Cultivation of cultural awareness and intercultural communicative competence in college English teaching[J], Educational Exploration, 2009.

[3] Byram,M. Cultural Studies in Foreign Language Education[M] . Clevedon ,Avon :Multilingual Matters ,1989.

[4] Stern ,H. H. Fundamental Concepts of Language Teaching[M] . London :Oxford University Press ,1983. 